\title{
Research Paper: The Knowledge of Emergency Medical Technicians of Prehospital Care Intensity Index of Spinal Cord Trauma in Ilam Province, Iran
}

\author{
Mehran Mozafari ${ }^{1}$ (D), Sima Zohari Anboohi ${ }^{1}$, Erfan Ghasemi ${ }^{1}$, Hamid Safarpour ${ }^{2}$ (D, Rahman Anvary ${ }^{2}$, Hossein Shiri ${ }^{*}$ (D) \\ 1. Department of Medical Surgical Nursing, School of Nursing and Midwifery, Shahid Beheshti University of Medical Sciences, Tehran, Iran \\ 2. Department of Nursing, School of Nursing and Midwifery, Ilam University of Medical Sciences, Ilam, Iran.
}

\begin{tabular}{|l|l|l}
\hline $\begin{array}{c}\text { Use yourdevice toscan } \\
\text { and readthe artice online }\end{array}$ & $\begin{array}{l}\text { Citation: Mozafari M, Zohari Anboohi S, Ghasemi E, Safarpour H, Anvary R, Shiri H. The Knowledge of Emergency Medi- } \\
\text { cal Technicians of Prehospital Care Intensity Index of Spinal Cord Trauma in Ilam Province, Iran. Health in Emergencies and } \\
\text { Disasters Quarterly. 2021; 6(3):139-146. http://dx.doi.org/10.32598/hdq.6.3.203.2 }\end{array}$ \\
doi: : http://dx.doi.org/10.32598/hdq.6.3.203.2
\end{tabular}

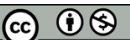

Article info:

Received: 13 Dec 2020

Accepted: 23 Feb 2021

Available Online: 01 Apr 2021

Keywords:

Knowledge, Prehospital care, Trauma, Spinal cord, Iran

\section{A B S T RACT}

Background: The knowledge of Emergency Medical Technicians (EMTs) plays a crucial role in the outcomes of traumatic patients. This study aimed to assess the knowledge of EMTs about the prehospital care intensity index of spinal cord trauma in Ilam Province, Iran.

Materials and Methods: This cross-sectional study was conducted on 98 EMTs chosen by the census sampling method. The study data were collected using a researcher-made questionnaire on the prehospital care intensity index of spinal cord trauma and were analyzed with SPSS 16.

Results: The knowledge of the prehospital care intensity index of spinal cord trauma was at the advanced level in $87.7 \%$ of EMTs and the intermediate level in $15.3 \%$ of EMTs. There was a significant relationship between the technician's knowledge score and variables such as age, work record, overtime hours, and the number of missions $(\mathrm{P}<0.05)$.

Conclusion: EMTs needed more specialized information on spinal trauma. It was recommended to hold in-service training programs more precisely and consider the training of necessary skills that most EMTs require.

\section{Introduction}

ccording to the World Health Organization (WHO), more than 5 million people die each year due to injuries. Based on this number, the injuries will be the seventh leading cause of death by 2030 [1]. This accounts for $9 \%$ of the world's deaths [1]. Traumatic consequences result in serious socioeconomic detriments that are relatively preventable. To reduce mortality, complications, and disabilities, it is necessary to provide injured patients with proper treatments and care services, beginning with prehospital care. Prehospital care is considered the first component of the traumatic care system $[2,3]$, whose efficiency has a vital role in the prognosis of traumatic patients. Traumatic spinal cord injury is the leading cause of morbidity and mortality worldwide. It is estimated that 768473 to 790695 people suffer from spinal cord injury each year [4]. Spinal cord injury, amongst various types of trauma, has the highest priority due to the consequences of spine injuries that often cause permanent

\section{* Corresponding Author:}

Hossein Shiri, MSc.

Address: Department of Medical Surgical Nursing, School of Nursing and Midwifery, Shahid Beheshti University of Medical Sciences, Tehran, Iran. E-mail: shiri.hossein43@gmail.com 
neuropathy in its sufferers [4]. As reported, nearly threefourth of traumatic events has led to spinal trauma in Australia, $52 \%$ of which were accompanied by spine injury [5]. In the UK, over half of the accident-induced spinal trauma resulted in permanent damages to the spinal cord. Patients with traumatic spine injuries are also vulnerable to neurological trauma caused by secondary injury to the spine during the therapeutic measures [6].

Continuous clinical examination and necessary initial interventions can prevent two major traumatic complications, namely neurogenic shock and spinal shock in spinetraumatic patients $[3,7]$. Since, a solid understanding of injury mechanisms and using an optimal emergency management pattern, including the prevention of secondary injuries by prompt patient's transference to an appropriate trauma center, are mainly sought in the care of patients with traumatic spine, the critical role of prehospital intensive care is the first step of traumatic care system [8-10].

As indicated in several studies, one of the main reasons for the poor performance of prehospital emergency staff was the lack of traumatic knowledge [11]. Ahn et al. found that about $2 \%$ of traumatic brain injuries are due to secondary injuries during the transfer of patients with spinal trauma to care centers, as well as the course of treatment by Emergency Medical Services (EMS) staff [6]. Norouzinia et al. reported that $82.6 \%$ of EMS interns had intermediate clinical knowledge, $10.9 \%$ had poor clinical knowledge, and $6.5 \%$ had advanced clinical knowledge once faced with a traumatic patient [12].

According to Kumar et al., the mean value of the staff knowledge and practice of prehospital care was lower than the average of three nursing groups [13]. Therefore, the likelihood of secondary injuries can be minimized through having considerable notice to promoting the existing EMS facilities as well as enhancing the knowledge and skill of care providers in the healthcare system to prevent any potential injury to traumatic patients during the early stages of caregiving and treatment [14]. Emergency medical services can determine the type of care needed on the patient's part based on clinical judgment using knowledge assessment scales. To evaluate the knowledge, awareness, and performance of EMTs, it is necessary to provide them with required training programs and measures.

Considering what was discussed about the significance of prehospital intensive care and the direct relationship between the incidence of trauma and role of a technician in the rehabilitation and prevention of temporary and permanent neuropathy in traumatic patients, it seems compulsory to train the staff for accomplishing an optimal knowledge and awareness in, at least, national level [15]. As just stated, spinal cord trauma is one of the most severe traumatic injuries, making patients incur substantial financial problems and severe health disorders during their lives, associated with a high mortality rate amongst these patients. Because research findings in Iran, unlike the global standard level, indicate the undesirable performance of prehospital EMTs in dealing with trauma due to their insufficient knowledge and few similar studies on patients with spinal trauma in Iran, the Deputy of Education in Emergency Department of Iran has been recently held in-service training courses on trauma. Consequently, the present study aimed to assess the knowledge of EMTs of prehospital care intensity index of spinal cord trauma.

\section{Materials and Methods}

The present descriptive study was conducted in EMS centers affiliated with Ilam University of Medical Sciences. Based on the census sampling method, 98 EMTs in Ilam City were selected. The inclusion criteria included the employment (fully-statured, contractual, corporate, conventional, and project-based) in disaster and emergency medical management centers, a minimum of 1 year of clinical work history in emergency wards, and informed consent to participate in the study. The exclusion criteria were unwillingness to participate in the study. The study data were collected using a researchermade questionnaire on the prehospital care intensity index of spinal cord trauma and a report sheet on clinical skills and performance. The demographic questionnaire included the participants' age, sex, marital status, education, the field of study, occupation, previous employment, type of employment, shift work status, overtime hours, job experience, in-service training programs, number of missions, and preservice trauma training.

Regarding the lack of a traumatic care protocol in Iran, the researchers of the present study developed a 19-item questionnaire with a 2-point scale. This questionnaire was based on preceding studies and used nursing instructions and guidelines for caring for patients with spinal trauma to evaluate EMTs' knowledge of prehospital care intensity index of spinal cord trauma. Each item was scored 1 if it was correct and 0 if it was incorrect. The resulting score ranged from 0 to 19 . Accordingly, the higher the scores, the higher the knowledge of intended participants. The researcher-made questionnaire was prepared based on existing scientific resources and tools such as books on the principles of prehospital emergency 
Table 1. Demographic characteristics of study subjects

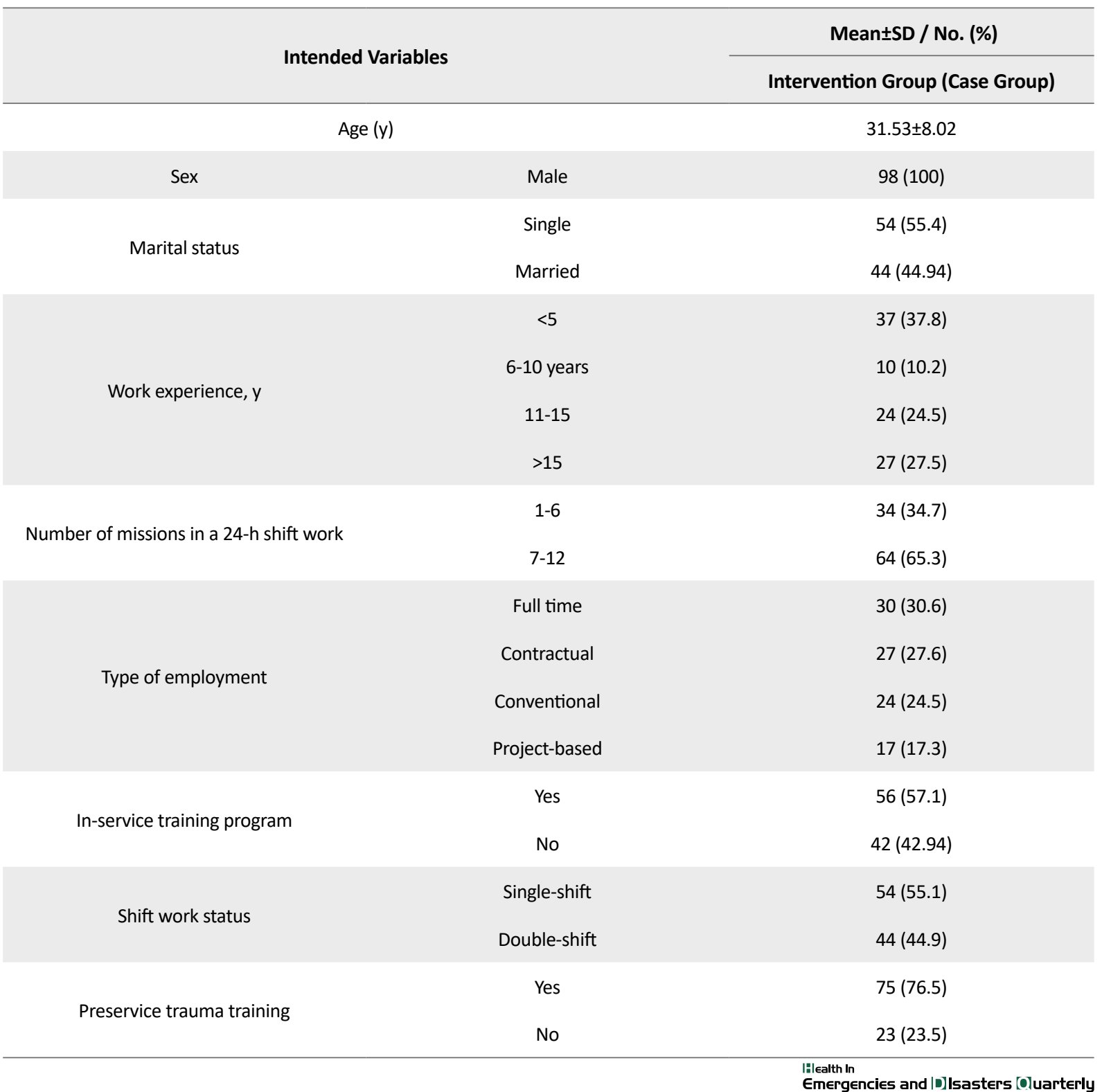

medicine and a training course on emergency care by Mistovich, Bledsoe, and Rhonda Beck [16, 17].

The validity and reliability of the questionnaire were verified by 15 faculty members of the Nursing Department and professors of the Emergency Department in the School of Nursing and Midwifery in Shahid Beheshti University of Medical Sciences, Iran. Once expert judgments were received, the necessary modifications were applied to the questionnaire under the supervision of the advisors described above and professors. Finally, its reliability was estimated using the test-retest method after the ultimate approval. To this end, data collection instruments (inventory, questionnaire, and report sheet) were completed and revised within a 14-day interval by 20 emergency technicians working at Ilam University of Medical Sciences. The internal consistency of which was obtained as 0.71 through calculating the Cronbach alpha.

Once permission and letter of recommendation were received from the Deputy of School of Nursing and Midwifery in Shahid Beheshti University of Medical Sciences, the researcher made necessary coordination with the "Disaster and Emergency Medical Management Center of Ilam Province". The researcher explained the purpose of the present study to the managers and authorities of the intended research environment to obtain the letter of authority for data collection and sampling. Afterward, the 
Table 2. Frequency distribution of emergency medical technicians knowledge of prehospital emergency cares in Ilam Province

\begin{tabular}{|c|c|c|}
\hline & Knowledge Level & No. (\%) \\
\hline & Low/Poor & $0(0)$ \\
\hline & Intermediate & $15(15.3)$ \\
\hline & High/Advanced & $83(84.7)$ \\
\hline & Items & Correct Responses \\
\hline 1 & Most vertebras damaged during vertebral column injury & $78(79.6)$ \\
\hline 2 & First encounter with patients suspected of spinal cord trauma & $82(83.7)$ \\
\hline 3 & The most effective way to prevent infections transmitted from the patient to the therapist & $79(80.6)$ \\
\hline 4 & Pulling the driver out of the burning tanker & $82(93.7)$ \\
\hline 5 & Fixation of patient's cervical spinal cord & $75(76.5)$ \\
\hline 6 & Traumatic patient lying in supine or prone position & $80(81.6)$ \\
\hline 7 & Time of fastening cervical collar (neck brace) to traumatic patients & $78(79.6)$ \\
\hline 8 & Non-prescription of oxygen within the respiratory rate limit & $75(76.5)$ \\
\hline 9 & Reduced consciousness due to direct strike to the spine or head during physical conflicts & $82(83.7)$ \\
\hline 10 & Fixation of chest movement for patients injured during electrical shock & $82(83.7)$ \\
\hline 11 & $\begin{array}{c}\text { Sudden right-side hemiparesis during log roll maneuver to remove the patient to the long back } \\
\text { board }\end{array}$ & $81(82.7)$ \\
\hline 12 & $\begin{array}{c}\text { The handling of medical devices used for the patient injured in sitting position and suspected of } \\
\text { spinal trauma }\end{array}$ & $77(78.6)$ \\
\hline 13 & Who commanded to move and lift the patient with a long back board & $83(84.7)$ \\
\hline 14 & Forceful lifting of the patient with appropriately distant hands to hold the long back board & $76(77.6)$ \\
\hline 15 & The ideal time for initial examination, fastening fixation, and transfer of traumatic patient & $78(79.6)$ \\
\hline 16 & Regular, continuous examination in severely injured and other stable patients & $77(78.6)$ \\
\hline 17 & The technique of jaw opening with a push without moving the neck & $85(86.7)$ \\
\hline 18 & Checking the airway of a traumatic patient & $73(74.5)$ \\
\hline 19 & Fixation of the entire backbone of a 3-year-old infant on a regular long back board & $73(74.5)$ \\
\hline
\end{tabular}

researcher invited EMTs of Ilam University of Medical Sciences by the consent of the Deputy of Education. All 98 subjects participated in the study after attending the explanatory sessions and providing informed consent. The study data were collected using a demographic inventory and a researcher-made survey questionnaire on the prehospital care intensity index of spinal cord trauma. For data collection, the technicians working in the training center of Ilam Emergency Department completed the demographic inventory and researcher-made questionnaire on prehospital emergency care for spinal trauma once they were assured of information confidentiality. Once data were collected, they were analyzed using descriptive statistics (mean, standard deviation, frequency, percentage) and inferential statistics of Mann-Whitney U test, Kruskal-Wallis test, Spearman correlation coefficient, 1-way ANOVA, and independent t-test in SPSS v. 16.

\section{Results}

The present study evaluated 98 EMTs of the prehospital Emergency Department at Ilam University of Medi- 
Table 3. Relationship between demographic characteristics and knowledge level

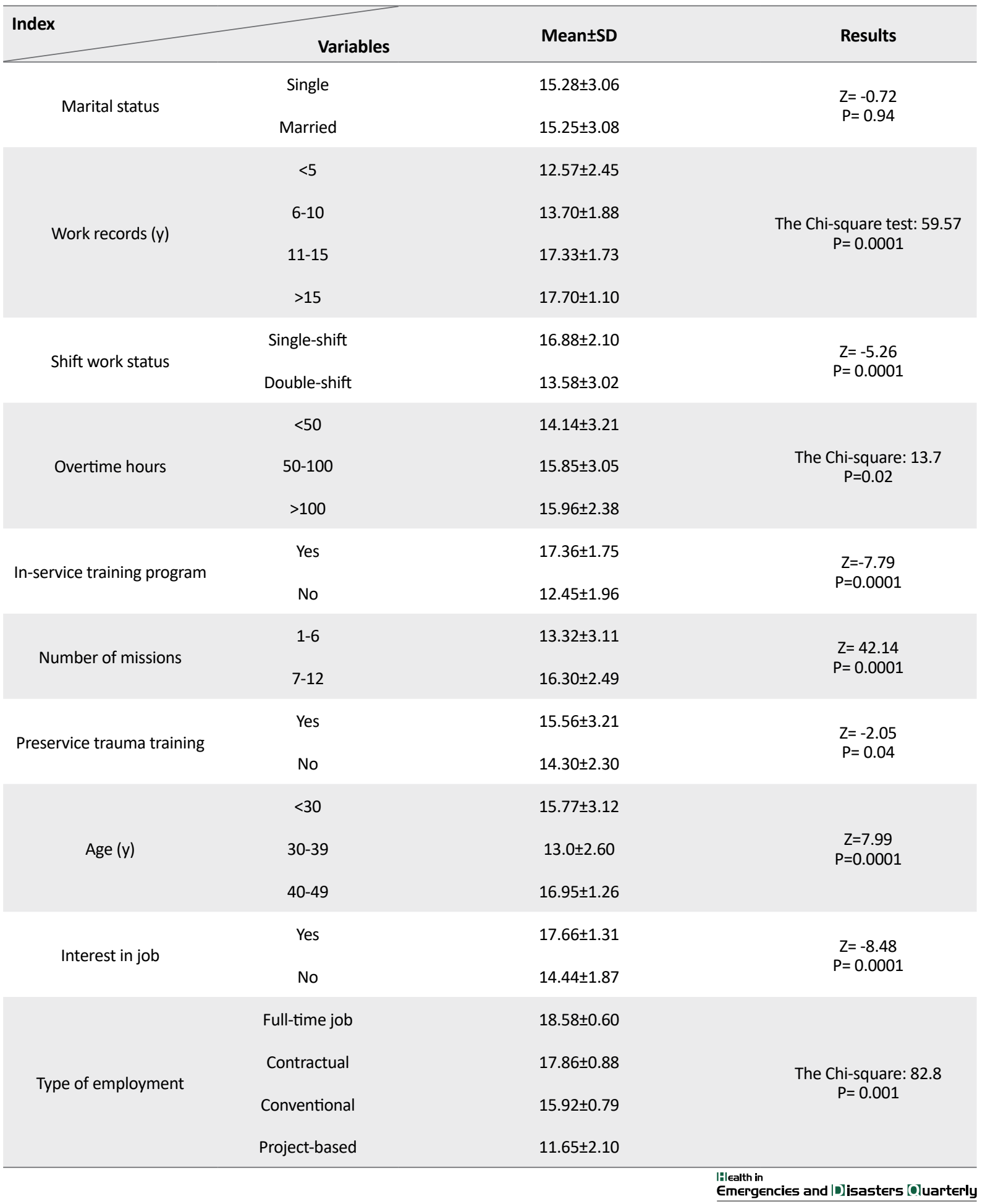

cal Sciences; $100 \%$ were male. The Mean \pm SD age of the subjects was $31.53 \pm 8.02$ years (range: 23 to 49 years). Almost $72.4 \%$ of the participants had $11-15$ years of clinical work history. The majority were single-shift workers (55.1\%). Almost $40.8 \%$ of staff worked overtime ranging from 50 to 100 hours, while $35.7 \%$ had less than 50 hours of overtime. About 57.1\% attended in-service training programs, and $76.5 \%$ had preservice trauma training. The number of missions in a 24-hour shift work ranged from 7 to 12 missions for most staff $(65.3 \%)$. Other demographics have been presented in Table 1 . 
Furthermore, the Mean \pm SD score of EMTs' knowledge of prehospital intensive care for spinal trauma was $15.27 \pm 3.06$ (out of 19 scores), varying from 8 to 19 . The knowledge of prehospital care for the traumatic spine was at the advanced level in 83 technicians (87.7\%) and intermediate level in 15 technicians (15.3\%). The highest percentage of correct responsiveness belonged to item 17 , i.e., the technique of jaw opening with a push without moving the neck $(86.7 \%)$, and the lowest percentage was pertained to items 18 and 19, i.e., checking the airway of a traumatic patient and fixation of the entire backbone of a 3-year-old infant on a regular long back board (Table 2).

The results regarding the relationship between EMS staff demographics and their knowledge level of prehospital care intensity index of spinal cord trauma indicated a significant direct relationship between their knowledge level and such demographics as age, work record, overtime hours, and the number of missions $(\mathrm{P}<0.05)$. Moreover, the mean knowledge level of full-time job and contractual job holders and those interested in their job was higher than other subjects $(\mathrm{P}<0.05)$. Besides, the mean score of knowledge showed a higher value amongst single-shift technicians than double-shift ones $(\mathrm{P}<0.05)$. Technicians attending in-service training programs or having preservice trauma training had a higher significant mean knowledge level than other staff $(\mathrm{P}<0.05)$, as displayed in Table 3.

\section{Discussion}

According to the results, a majority of EMTs had advanced knowledge of prehospital care. The highest percentage of correct responsiveness belonged to item 17 , i.e., the technique of jaw opening with a push without moving the neck, and the lowest percentage pertained to items 18 and 19, i.e., checking the airway of a traumatic patient and fixation of the entire backbone of a 3-year-old infant on a regular long back board. Also, the percentage of correct responses ranged from $7.5 \%$ to $87.7 \%$. 15 . Hunt et al. indicated that the mean knowledge of trauma scored 28.02 out of 46 amongst EMS staff, $78.1 \%$ of whom were at an intermediate level of knowledge [15]. According to Ziabari et al., about $70 \%$ of interns had an intermediate and even lower knowledge level of cervical collar use in traumatic patients [18]. Accordingly, the lowest knowledge was associated with the predictors of cervical and lumbar spinal injury (98.8\%) and the severity of injury (95.0\%) [19].

Norouzinia et al. reported that $82.6 \%$ of EMS interns were intermediate in their knowledge of trauma [12].
Parvaresh-Masoud et al. displayed that the Mean \pm SD knowledge of prehospital care for patients with chest trauma was $3.46 \pm 1.10$ amongst EMTs, indicating a low knowledge level [20]. In a study by Dehghannezhad et al., the results showed that $67.82 \%$ and $84.4 \%$ of EMTs have intermediate to low knowledge regarding trauma care [21]. According to Kumar et al., the mean value of staff knowledge and practice of prehospital care was lower than the average of three nursing groups [13], which was inconsistent with the present study results. The inconsistency between the present study results and other studies may contribute to the difference in their evaluation of knowledge level. Kumar et al. evaluated the knowledge level of both hospital, and prehospital emergency cares amongst three groups of EMTs, EMS nurses, and emergency medicine specialists, while the present study evaluated the knowledge of prehospital care amongst EMTs only [13].

Nevertheless, if the present study is compared with $\mathrm{Ku}-$ mar's three groups of subjects, its results would be in line with the findings of Kumar and associates. Even though the overall knowledge of intended participants was at the highest level in the present study, their knowledge of checking the airway of a traumatic patient was at a low level. However, concerning the significance of medical emergency training on the role of airway obstruction in hypoxemia, hypercapnia, and risky acidosis induced by poor ventilation (that can ultimately cause not only permanent damage to the brain, heart, and lungs but also death), the prehospital EMTs should increase their knowledge level in this area. Furthermore, considering that the slightest negligence and inappropriate use of logrolling maneuver for moving patients with cervical and lumbar spine trauma can result in permanent and irreversible damages or even death, technicians' insufficient knowledge of constraining the entire backbone of a 3-year-old infant on a regular long back board could cause serious consequences. Therefore, it is vital to pay attention to the significance of these two issues in the principles of prehospital emergency cares on the part of EMTs.

The present study participants did not have a significant role and effective management in checking the airway of a traumatic patient and constraining the entire backbone of infants. In contrast, many patients, especially adolescents and children injured in accidents, suffered severe damage to their vertebral column and spinal cord. They were at the risk of permanent disability and death and imposed huge costs on the health system and society. Many of these cases, nonetheless, could be prevented using appropriate principles and medical equipment in out-of-hospital environments. 
The present study findings demonstrated a significant direct relationship between the mean score of knowledge level and such demographics as age, work record, overtime hours, and the number of missions in the present study $(\mathrm{P}<0.05)$. Moreover, the mean knowledge level of full-time job and contractual job holders and those interested in their job was higher than other subjects $(\mathrm{P}<0.05)$. Besides, the mean score of knowledge showed a higher value amongst single-shift nurses than double-shift ones $(\mathrm{P}<0.05)$. Technicians attending in-service training programs or having preservice trauma training had a higher mean knowledge level than other staff, indicating a statistically significant difference $(\mathrm{P}<0.05)$. The findings of such researchers as Heidari investigating the effect of simulated execution on the knowledge and preparedness of nursing students [22], Bartley et al. studying the effect of watching hospital maneuver film for increasing staff preparedness [23], and Idrose et al. determining the impact of classroom-based training and simulated maneuver on the preparedness of airline medical staff in accountability for potential disasters promoted the effectiveness of training processes in medical staff preparedness for meeting and fulfilling their responsibilities at the time of crisis and disaster $[24,25]$. It means that the staff preparedness and assurance of their ability to meet the needs of patients at the time of difficult trauma-inducing conditions is significantly affected by preservice training and experiences of medical staff.

\section{Conclusion}

The present study results indicated that the majority of EMTs had sufficient knowledge of prehospital emergency cares for patients with spinal cord trauma. However, due to the significant difference between the observed scores and actual scores, it seems necessary to develop or introduce a precise resource based on the latest guidelines on prehospital emergency care and improve the appropriateness of care procedures for traumatic patients. By doing so, the weaknesses of EMTs could be minimized, and their theoretical knowledge could be increased as the basis of efficient performance.

\section{Study limitations}

It is worth noting that since the present study targeted a limited number of EMTs working in prehospital emergency centers affiliated to Ilam University of Medical Sciences, it is not feasible to generalize the results to all the prehospital emergency staff. Thus, further studies are recommended to target a more extensive sampling at the national level.

\section{Ethical Considerations}

\section{Compliance with ethical guidelines}

The study was approved by the Ethics Committee of Shahid Beheshti University of Medical Sciences in Tehran (Code: IR.SBMU.PHNM.1396.751). All ethical principles are considered in this article. The participants were informed about the purpose of the research and its implementation stages. They were also assured about the confidentiality of their information and were free to leave the study whenever they wished, and if desired, the research results would be available to them.

\section{Funding}

The paper was extracted from the MSc. thesis of the first author at the Department of Medical Surgical Nursing, School of Nursing and Midwifery, Shahid Beheshti University of Medical Sciences, Tehran.

\section{Authors' contributions}

All authors equally contributed to preparing this article.

\section{Conflict of interest}

The authors declared no conflict of interest.

\section{References}

[1] World Health Organization. Injuries and violence: The facts 2014. Geneva: World Health Organization; 2014. https:// apps.who.int/iris/handle/10665/149798

[2] Murad MK, Larsen S, Husum H. Prehospital trauma care reduces mortality. Ten-year results from a time-cohort and trauma audit study in Iraq. Scandinavian Journal of Trauma, Resuscitation and Emergency Medicine. 2012; 20(1):13. [DOI:10.1186/1757-7241-20-13] [PMID] [PMCID]

[3] Galeiras Vázquez R, Ferreiro Velasco ME, Mourelo Fariña M, Montoto Marqués A, Salvador de la Barrera S. [Update on traumatic acute spinal cord injury. Part 1 (Spanish)]. Medicina Intensiva. 2017; 41(4):237-47. [DOI:10.1016/j.medin.2016.11.002] [PMID]

[4] Kumar R, Lim J, Mekary RA, Rattani A, Dewan MC, Sharif SY, et al. Traumatic spinal injury: Global epidemiology and worldwide volume. World Neurosurgery. 2018; 113:e345-63. [DOI:10.1016/j.wneu.2018.02.033] [PMID]

[5] Hauswald M. A re-conceptualisation of acute spinal care Emergency Medicine Journal. 2013;30(9):720-3. [DOI:10.1136/ emermed-2012-201847] [PMID]

[6] Ahn H, Singh J, Nathens A, MacDonald RD, Travers A, Tallon J, et al. Pre-hospital care management of a potential spinal cord in- 
jured patient: A systematic review of the literature and evidencebased guidelines. Journal of Neurotrauma. 2011; 28(8):1341-61. [DOI:10.1089/neu.2009.1168] [PMID] [PMCID]

[7] Nishijima DK, Simel DL, Wisner DH, Holmes JF. Does this adult patient have a blunt intra-abdominal injury? JAMA. 2012 307(14):1517-27. [DOI:10.1001/jama.2012.422] [PMID] [PMCID]

[8] Bazyar J, Farrokhi M, Khankeh H. Triage systems in mass casualty incidents and disasters: A review study with a worldwide approach. Open Access Macedonian Journal of Medical Sciences. 2019; 7(3):482-94. [DOI:10.3889/oamjms.2019.119] [PMID] [PMCID]

[9] Bazyar J, Farrokhi M, Salari A, Khankeh HR. The principles of triage in emergencies and disasters: A systematic review. Prehospital and Disaster Medicine. 2020; 35(3):305-313. [DOI:10.1017/ S1049023X20000291] [PMID]

[10] Delshad V, Sabzalizadeh S, Moradian MJ, Safarpour H, Malekyan L, Shemshadi H, et al. Epidemiology of accidents in Tehran emergency medical service during 2012 to 2013. Trauma Monthly. 2018; 23(1):e61871. [DOI:10.5812/traumamon.61871]

[11] Butler MW, Adefuye AO. Assessing the knowledge of emergency medical care personnel in the Free State, South Africa, on aspects of paediatric pre-hospital emergency care. The Pan African Medical Journal. 2019; 32:98-. [DOI:10.5812/traumamon.61871] [PMID] [PMCID]

[12] Norouzinia R, Ahmadi M, Seidabadi M. [Knowledge and clinical competence of medical emergencies students in facing trauma (Persian)]. Iranian Journal of Emergency Medicine. 2016 3(2):73-7. https://journals.indexcopernicus.com/api/file/viewByFileId/341472.pdf

[13] Kumar S, Agarwal AK, Kumar A, Agrawal GG, Chaudhary S, Dwivedi V. A study of knowledge, attitude and practice of hospital consultants, resident doctors and private practitioners with regard to pre-hospital and emergency care in Lucknow. Indian Journal of Surgery. 2008; 70(1):14-8. [DOI:10.1007/s12262-0080003-2] [PMID] [PMCID]

[14] Rajani RR, Ball CG, Montgomery SP, Wyrzykowski AD, Feliciano DV. Airway management for victims of penetrating trauma: Analysis of 50,000 cases. American Journal of Surgery. 2009; 198(6):863-7. [DOI:10.1016/j.amjsurg.2009.08.013] [PMID]

[15] Hunt R, American Academy of Orthopaedic Surgeons. Advanced emergency care and transportation of the sick and injured. Burlington, Massachusetts: Jones \& Bartlett Publishers; 2011. https://www.google.com/books/edition/Advanced Emergency/gd-ycQAACAAJ?hl=en

[16] Mistovich J, Karren K. Prehospital Emergency Care. $11^{\text {th }}$ edition. London: Pearson; 2018. https:/ / www.pearson.com/uk/educators/higher-education-educators/program/MISTOVICH Prehospital-Emergency-Care-11th-Edition/PGM1855278. html?tab=formats

[17] Bledsoe BE. Essentials of A \& P for Emergency Care. $1^{\text {st }}$ edition. Hoboken, New Jersey: Prentice Hall; 2010. https://www amazon.com/Bryan-Bledsoe-Essentials-Emergency-Care/dp/ B00N4EQCQA

[18] Ziabari SM, Kasmaei VM, Pourshafiei SH, Saadatmand S. Knowledge and practice of medical interns regarding use of neck collar in trauma patients: A cross-sectional study. Iranian Journal of Emergency Medicine. 2018; 5:e11. https://www.semanticscholar.org/paper/Knowledge-and-Practice-of-medicalInterns-Regarding-Ziabari-Kasmaei/8f2648516d1f13f5c88f5ad5f c403f742e90068
[19] Fallahi Khoshknab M, Khankeh H, Hosseini M, Hosseinzadeh S, Haghi Monie N. Evaluation of clinical skills of medica emergency personnel in Tehran Emergency Center confronting the trauma. Journal of Health Promotion Management 2012; 1(4):16-24. http://jhpm.ir/browse.php?a_code=A-10172-1\&slc_lang=en\&sid=1

[20] Parvaresh Masoud M, Farhadloo R, Vahedian M, Kashaninejad M, Hasanpoor L, Mohebi S. [A Comparison between the effects of scenario and lecture-based education methods on knowledge and attitude of emergency medical technicians towards patients with chest trauma (Persian)]. Qom University of Medical Sciences Journal. 2016; 10(5):47-54. http:// journal.muq.ac.ir/article-1-1021-en.html

[21] Dehghannezhad J, Rahmani F, Rajaei Ghafouri R, Hassankhani H, Dadashzadeh A, Heydarpoor Damanabad Z. Promotion of knowledge, skill, and performance of emergency medical technicians in prehospital care of traumatic patients: An action-research study. Archives of Trauma Research. 2020; 9(2):81-6. [DOI:10.4103/atr.atr_112_19]

[22] Heidari M, Shahbazi S. Assessment of Emergency Medical Services (EMS) staff's knowledge and practice about principles and equipment used for patient handling in EMS centres of isfahan province. Journal of Research Development in Nursing \& Midwifery. 2015; 12(1):111-7. http://nmj.goums. ac.ir/article-1-719-en.html

[23] Bartley B, Fisher J, Stella J. Video of a disaster drill is effective in educating registrars on the hospital disaster plan. Emergency Medicine Australasia. 2007; 19(1):39-44. [DOI:10.1111/j.1742-6723.2006.00916.x] [PMID]

[24] Idrose AM, Adnan WA, Villa GF, Abdullah AH. The use of classroom training and simulation in the training of medical responders for airport disaster. Emergency Medicine Journal (EMJ). 2007; 24(1):7-11. [DOI:10.1136/emj.2006.036202] [PMID] [PMCID]

[25] Badjatia N, Carney N, Crocco TJ, Fallat ME, Hennes HM Jagoda AS, et al. Guidelines for prehospital management of traumatic brain injury, $2^{\text {nd }}$ edition. Prehospital Emergency Care. 2008; 12(Suppl 1):S1-52. [DOI:10.1080/10903120701732052] [PMID] 